UDK $615.9,614.7$

\title{
COMPARISON OF TOXICITY OF AQUEOUS SUSPENSION OF NANO-AND MICROFINE SILICA IN SUBCHRONIC EXPERIMENT
}

\author{
M.A. Zemlyanova1', V.N. Zvezdin'1, A.A. Dovbysh'1, T.I. Akafyeva ${ }^{1,2}$ \\ ${ }^{1} \mathrm{FBSI}$ "Federal Scientific Center for Medical and Preventive \\ Health Risk Management Technologies", \\ 82, Monastyrskaya St., Perm, 614045, Russia, \\ 2 FSBEI HPE "Perm State National Research University", \\ 15, Bukireva St., Perm, 614990, Russia
}

\begin{abstract}
In subchronic experiment on Wistar's white male rats the negative effects have been studied and the comparative assessment of toxicity of an aqueous suspension of nano- and microfine silicon dioxide has been carried out. It was found that by intragastric administration for 90 days of the dose of $14.6 \mathrm{mg} / \mathrm{kg}$, corresponding to the predicted threshold dose (LOAEL), the aqueous suspension of nanosized silicon dioxide causes immune irritating, cytolytic and inflammatory effects, verified by the deviation of hematologic parameters and morphological changes in tissues bodies / or target systems (liver, stomach, jejunum and colon, immune system). Micro-sized silica causes predominantly an inflammatory effect in the mucosa of stomach, jejunum and colon.

Key words: silica nanoparticles, microparticles, negative effects, subchronic toxicity, intragastric administration, experimental studies.
\end{abstract}

Today, according to the U.S. Congressional Research Service, nanotechnologies are used in the production of 80 groups of consumer products and 600 types of raw materials, component parts and industrial equipment [12]. Accelerated rates of nanopowder production in the world, the biggest share of which is silicon dioxide (up to $40 \%$ of the world nanopowder production) [3] determine their leading position in terms of application in the most prospective industries: nanooptics, nanoelectronics, nanobiotechnologies, pharmaceuticals, etc.

Due to rapid development of the nanotechnology market, the issues of nanotoxicology and biosafety of the utilized nanomaterials are becoming more important and serve as a vast area for research. The analysis of available experimental materials about the biological effects of nanoparticles and nanomaterials is included in a number of scientific publications by international and Russian researchers [7,9]. The assumption based on these publications is that toxicity of nanoparticles is higher than the particles of the same chemical composition in the micro- and macrorange. At the same time, the comparative date on the toxicity of nano- and

(C) Zemlyanova O.V., Zvezdin A.V., Dovbish O.A., Akafyeva V.B., 2014

Zemlyanova Marina Aleksandrovna - MD, Head of Department of Biochemical and Cytogenetic Diagnostic Methods (e-mail: zem@fcrisk.ru, tel.: +7 (342) 236-39-30).

Zvezdin Vasiliy Nikolaevich - MD, senior research associate of the Laboratory of Biochemical and Nanosensor Diagnosics (e-mail: zvezdin@fcrisk.ru, tel.: +7 (342) 236-39-30).

Dovbish Anastasia Aleksandrovna - toxicologist of the Laboratory of Metabolism and Pharmacokinetics (e-mail: dovnastja@yandex.ru, tel.: +7 (342) 236-39-30).

Akafyeva Tatiana Igorevna - expert on nanotechnologies of the Laboratory of Biochemical and Nanosensor Diagnostics (e-mail: akafieva@fcrisk.ru, tel.: +7 (342) 236-39-30). 
microparticles under chronic and subchronic exposure is very scarce and scattered. Given the advent of mass produced product with which the population is in close contact, identification and comparative evaluation of the negative effects associated with consistent exposure to nanosized silicon dioxide is very important.

The purpose of the research is to investigate and compare the subchronic toxicity of the aqueous silicon dioxide nano- and microparticles administered intragastically. aterials and methods. In the course of the studies, we used aqueous nanosized silicon dioxide $(\mathrm{SiO} 2 \times$ $0,14 \mathrm{H} 2$ ) synthesized by the method of liquid-crystal templating that produces materials with unique textural and structural characteristics (large specific surface area, narrow pore-size distribution) $[6,11]$. Biodistilled water served as the matrix for the aqueous suspension. For the comparative analysis of the subchronic toxicity effects, we used the nanoparticles of the aqueous silicon dioxide $(\mathrm{SiO} 2 \times 0,08 \mathrm{H} 2 \mathrm{O})$ obtained by Stober synthesis [10] (synthesis conducted at the multiphase dispersed systems laboratory at the Institute of Technical Chemistry, the Ural Office of the Russian Academy of Sciences).

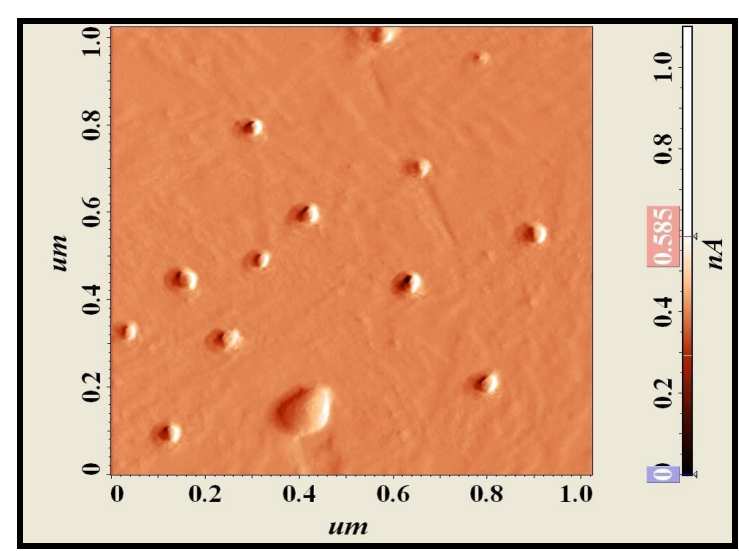

$a$

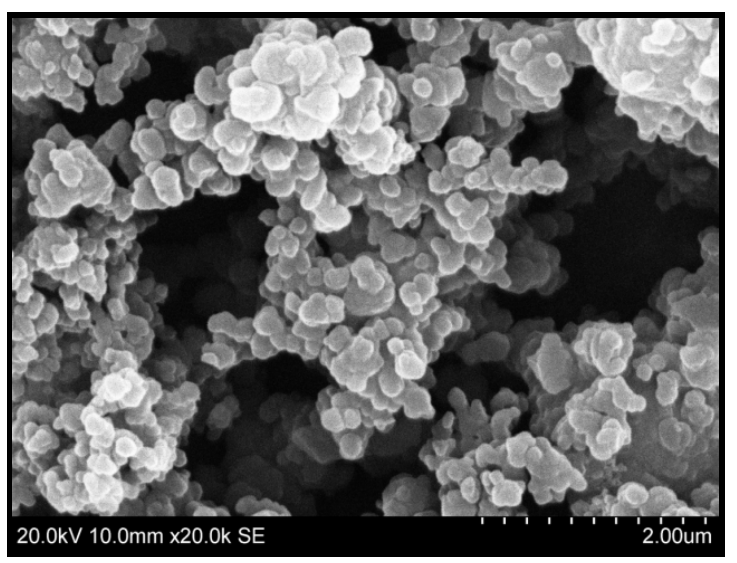

$b$

Figure 1. Synthesized nanoparticles of the silicon dioxide: $\mathrm{a}$ - AFM; b - electronic microscopy

Sixty-seven percent of the nanoparticles in the test sample had an elliptical contour, minor axis sized $25-35 \mathrm{~nm}$, and $33 \%$ had a spherical contour $25 \mathrm{~nm}$ in diameter (Figure 1). The microparticles of silicon dioxide were of 'traditional' dispersion (sized 1,63-2,35 $\mu \mathrm{m}$ in 100\% cases) of nonspherical contour. Nanodispersed silicon dioxide had a specific surface area of $96,96 \mathrm{~m} 2 / \mathrm{g}$ which corresponds with that of the nanosized range of amorphic silicon dioxide particles (from 50 to $380 \mathrm{~m} 2$ per $1 \mathrm{~g}$ of substance) and by 7,6 times exceeds the specific surface area of a microdispersed analogue $(12,54 \mathrm{~m} 2 / \mathrm{g})$. 
The silicon concentration in the aqueous suspension of nanosized silicon dioxide determined by AFM in acetylene/oxygen flames using Perkin Elmer 3110 analyzer (Perkin Elmer Inc., USA) totaled $65 \mathrm{mg} / \mathrm{cm} 3$, microsized analogue $-40 \mathrm{mg} / \mathrm{cm} 3$.

Immediately before the analytical investigation, we conducted an ultrasonic cleaning of the suspension using Sonopuls Hd 3200 Bandelin (Germany) at the room temperature, for 2 minutes, in the continuous pulsation mode at $65 \%$ power to prevent the formation of the aggregates and agglomerates in the liquid phase in the ageing conditions for a homogeneous distribution of $\mathrm{SiO} 2$ particles.

The experimental studies were conducted using male white Wistar rats $(190 \pm 20 \mathrm{~g})$ in the amount of 30 species (10 rats per group) provided by Andreyevka nursery at the Scientific Center of Biomedical Technologies, Russian Academy of Sciences (Laboratory regulation: decree by the Russian Ministry of Public Health and Social Development №708n of August 23, 2010). The operations with the experimental animals were conducted in accordance with the Guidelines for the Ethic Care and Use of Laboratory Animals (ILAR, DELS) [5]. The animals were kept under standard vivarium conditions with semisynthetic diet the nutritious and biological value of which completely met the physiological requirements. Access to food and water was not limited. The quarantine period before the experiment totaled 14 days.

The comparative analysis of the subchronic toxicity effects was conducted using a dose of $14,6 \mathrm{mg} / \mathrm{kg}$ body weight (1/250 LD50) that corresponds with the maximum tolerance dose of subacute experiment (LOAEL) determined based on the assessment of acute toxicity of aqueous silicon dioxide in nanosized form [4]. Aqueous suspension of nanosized silicon dioxide was administered to the animals by intragastrically using a feeding tube in a volume of $0,3 \pm 0,1 \mathrm{~cm} 3$ (group 1 - experimental), microsized silicon dioxide - in the amount of 0,6 $\pm 0,1 \mathrm{~cm} 3$ (group 2 comparison). Control animals received bidistilled water intragastrically to the maximum extent $0,6 \pm 0,1 \mathrm{~cm} 3$ (group 3 - control). The experiment lasted 90 days.

The animals of all groups underwent blood sampling from the tail vein; additionally, we measured hematological and biochemical indicators prior to (the base background) and on the 90th day of the experiment. The list of analyzed indicators, based on the results of the preliminary risk assessment of nanosized silicon dioxide allowed to identify the development of negative effects and to assess the functional state of organs / systems or target:

- blood and blood-forming organs (hemoglobin concentration, hematocrit, total erythrocyte count, mean corpuscular volume and hemoglobin concentration in whole blood);

- immune system (the relative number of eosinophils, lymphocytes, eosinophil blood lymphocyte index); 
- liver (the content of malondialdehyde (MDA), lipid hydroperoxide (GL), the activity of the antioxidant status (AOS), superoxide dismutase (SOD), alanine aminotransferase (ALT), aspartate aminotransferase (ASAT), Gamma-glutamyl transferase (GTP) serum);

- GI (white blood cell count, wbc whole blood levels of C-reactive protein and serum proteinogramma).

The studied indicators were determined in accordance with the automatic hematology protocol (Coulter Ac * T 5diff AL, Beskman Culter, USA), biochemical (Konelab20, Thermo Scientific, Finland), enzyme immunoassay (Infinite-F50, Tecan, Austria) analyzers.

To assess the significance of differences of the data obtained, we used t-Student criterion (comparison of the experimental and control groups by variables). The differences of the results were statistically significant at $\mathrm{p} \leq 0,05[2]$.

The animals were removed from the experiment on the 90th day using carbon dioxide euthanasia. To study the morphological changes in the tissues of internal organs in experimental animals, we selected visceral organs (lungs, heart, gastrointestinal tract, liver, spleen, kidneys) using the Shore method of complete evisceration. The brain and femur were removed for histological analysis with the help of a specialized tool.

Morphological examination included fixing of the material in $10 \%$ neutral buffered formalin, dehydration in alcohols of increasing concentrations, impregnating pieces with chloroform and paraffin, and then filling with the homogenized medium Histomix. 4 micron thick sections were produced on a luge microtome JUNG SM 2000R (Leica, Germany) and stained by the standard technique with hematoxylin and eosin. The obtained histological preparations were investigated in light-optical microscope Axiostar (Carl Zeiss, Germany).

Results and discussion. Research and comparative evaluation of abnormalities in hematological and biochemical parameters of blood, morphological changes in tissues of internal organs allowed establishing the negative effects that characterize the toxic effect of the test substances.

In experimental animals, one group showed cytolytic effect realized through activation of lipid peroxidation of cell membranes, by significant increase in the level of lipid hydroperoxides and MDA in serum in 1.5 and 1.9 times, respectively, relative to control values $(\mathrm{p}=0.001)$ (Table I).

The animals treated with microfine analog showed a significant increase in lipid hydroperoxide levels in serum of 1.3 times compared to control $(\mathrm{p}=0.039)$. Compared to lipid peroxidation in animals of group 1, we determined depletion of reserves of antioxidant protection. 


\section{Biochemical and hematological blood parameters, toxic effects with intragastrical administration of nano- and microdispersed silicon dioxide to Wistar rats for 90 days}

\begin{tabular}{|c|c|c|c|c|}
\hline Effect & Indicator & $\begin{array}{c}\text { Nanosized silicon } \\
\text { dioxide }\end{array}$ & $\begin{array}{l}\text { Microsized silicon } \\
\text { dioxide }\end{array}$ & Control \\
\hline \multirow{8}{*}{ Cytological } & $\mathrm{MDA}, \mu \mathrm{mol} / \mathrm{cm}^{3}$ & $3,4 \pm 0,4^{*}$ & $2,4 \pm 0,3$ & $2,3 \pm 0,2$ \\
\hline & $\mathrm{GL}, \mathrm{mol} / \mathrm{dm}^{3}$ & $59,7 \pm 16,6^{*}$ & $40,2 \pm 3,8^{*}$ & $30,9 \pm 3,0$ \\
\hline & $\mathrm{SOD}, \mathrm{H \Gamma} / \mathrm{cm}^{3}$ & $3,7 \pm 0,6^{*}$ & $5,5 \pm 0,4$ & $5,5 \pm 0,1$ \\
\hline & $\mathrm{AOS}, \mu \mathrm{mol} / \mathrm{dm}^{3}$ & $81,3 \pm 8,4^{*}$ & $170,6 \pm 4,5$ & $174,6 \pm 17,3$ \\
\hline & $\mathrm{ALT}, \mathrm{E} / \mathrm{dm}^{3}$ & $65,5 \pm 18,52 *$ & $54,8 \pm 8,8$ & $55,7 \pm 4,3$ \\
\hline & ASAT, E/ $\mathrm{dm}^{3}$ & $122,3 \pm 59,3$ & $130,5 \pm 27,7$ & $129,1 \pm 13,1$ \\
\hline & $\mathrm{GTP}, \mathrm{E} / \mathrm{dm}^{3}$ & $4,1 \pm 0,4$ & $3,7 \pm 0,5$ & $3,9 \pm 0,4$ \\
\hline & Target organ & Liver & - & - \\
\hline \multirow[b]{2}{*}{ Inflammatory } & СРБ, $\mathrm{mg} / \mathrm{dm}^{3}$ & $8,3 \pm 0,7^{*}$ & $7,4 \pm 0,7 *$ & $5,25 \pm 0,21$ \\
\hline & Target organ & $\begin{array}{l}\text { Stomach, empty and } \\
\text { middle intestine }\end{array}$ & $\begin{array}{l}\text { Stomach, empty and } \\
\text { middle intestine }\end{array}$ & - \\
\hline \multirow[t]{2}{*}{ Immune irritation } & $\begin{array}{l}\text { Eosinophilic-lymphocytic } \\
\text { index, standard unit }\end{array}$ & $0,02 \pm 0,006^{*}$ & $0,0034 \pm 0,006$ & $0,0032 \pm 0,003$ \\
\hline & Target organ & Spleen & - & - \\
\hline
\end{tabular}

N o t e : * Statistically significant differences with the control indicator $(p \leq 0,05)$.

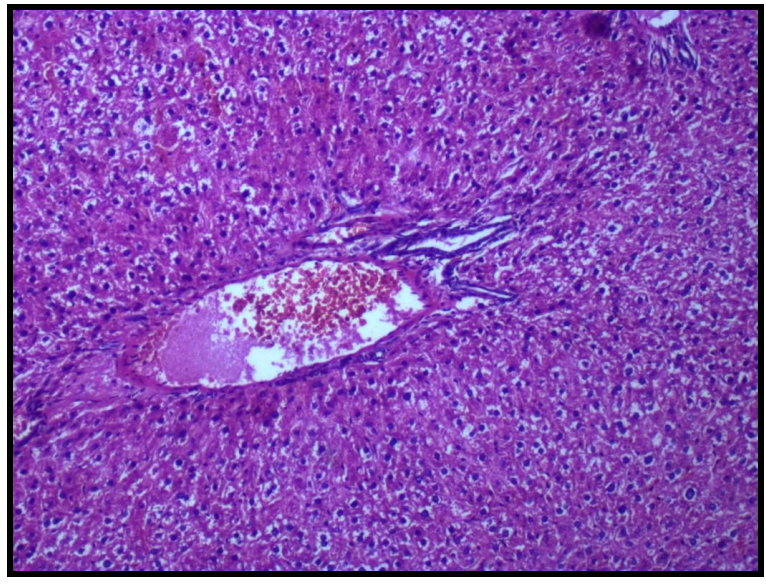

a

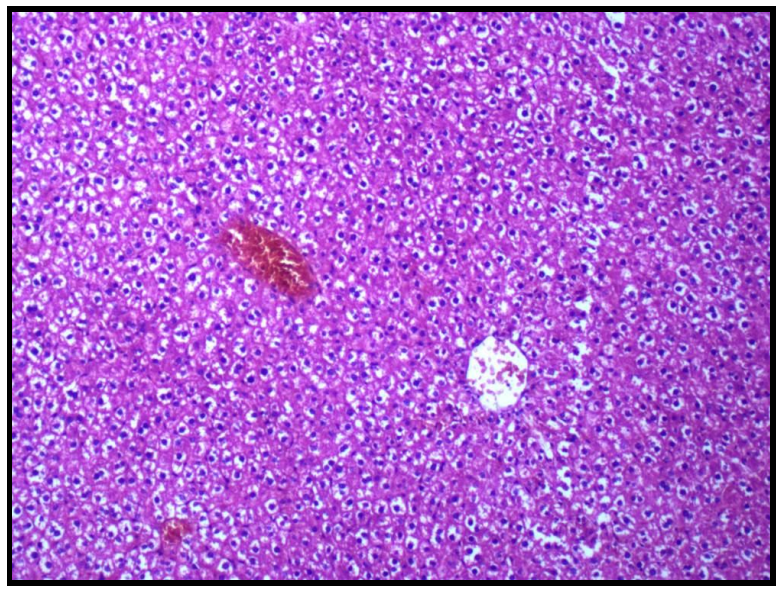

b

Figure 2. Rat liver at the 90th day of the experiment with the test compounds administered intragastrically at a dose of $14.6 \mathrm{mg} / \mathrm{kg}$. Ematoxylin and eosin: a - nanosized silicon dioxide, magn. $\times 400$; $\mathrm{b}-$ microsized silicon dioxide, magn. $\times 200$

This is evidenced by a significant decrease in SOD activity and AOS serum by 1.5 and 2.2 times compared to the values of the control group $(p=0,001-0,007)$. Indicators of the antioxidant system in group 2 animals during the whole experiment corresponded to the control level.

The changes indicate the development of oxidant-antioxidant imbalance that, in turn, can cause structural damage to the bilipid layer of the cell membrane through the preferential oxidation of unsaturated fatty acids [8]. The consequence of this is a disruption of membrane association and activity of enzymes, oxidation of SH-groups of transmembrane proteins and formation of oxidized lipids complexes with proteins to promote polymerization of protein 
molecules [1]. The specified range of molecular pathology leads to the destruction of cellular and subcellular membranes of hepatocytes (cytolysis effect), which may lead to an increase in activity in the serum of intracellular enzymes. The initial manifestations of the cytolytic effect was registered in the animals of group 1 with increased activity of serum ALT by 1.2 times $(\mathrm{p}=$ 0.041). In the animals group 2 , the enzyme activity of the control group was adequate. The change in the morphological structure of the liver cells confirmed enhanced cytolytic activity. We revealed that in the experimental animals of group 1, hepatocytes are in a fine-focal hydropic degeneration state, the cytoplasm of the cells (especially subcapsular) is optically transparent. In the group of animals receiving microsized analogue, no increase in the activity of intracellular enzymes in the blood serum and morphological changes in the cells or the liver were registered (Fig. 2).

Inflammatory effects were registered in the animals of the compared groups with an increased level of C-reactive protein in serum by 1.6 and 1.4 times, respectively, relative to the control group ( $\mathrm{p}=0,001-0,031)$. A histological study identified the presence of inflammatory changes in the digestive tract of animals of both groups: 1 and 2, which are characterized by moderate lymphomicrophagal infiltration doped with single plasma cells and eosinophils in the submucosal layer of the stomach, swelling of the mucous membrane of the jejunum and colon (Fig. 3, 4).

In the animals of the control group (data not shown) in the histological preparations of the jejunum, the wall structure was preserved, the intestinal villi were thin, with loose stroma traced goblet cells.

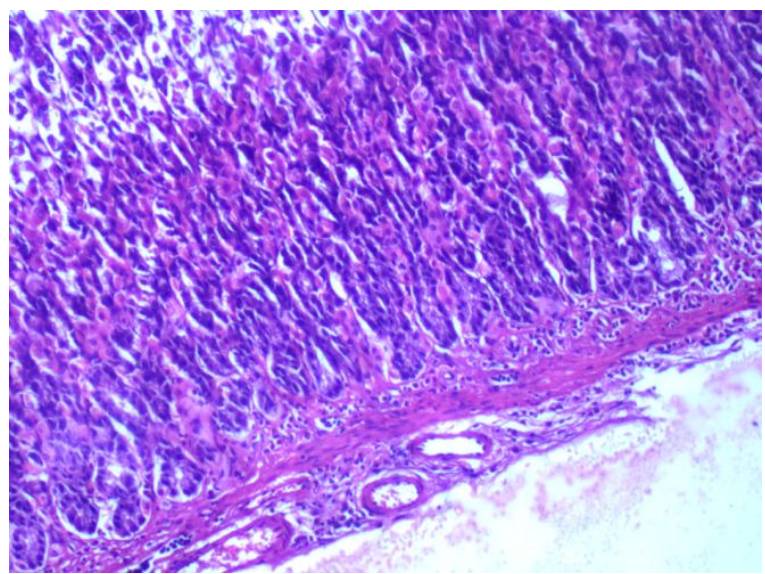

$a$

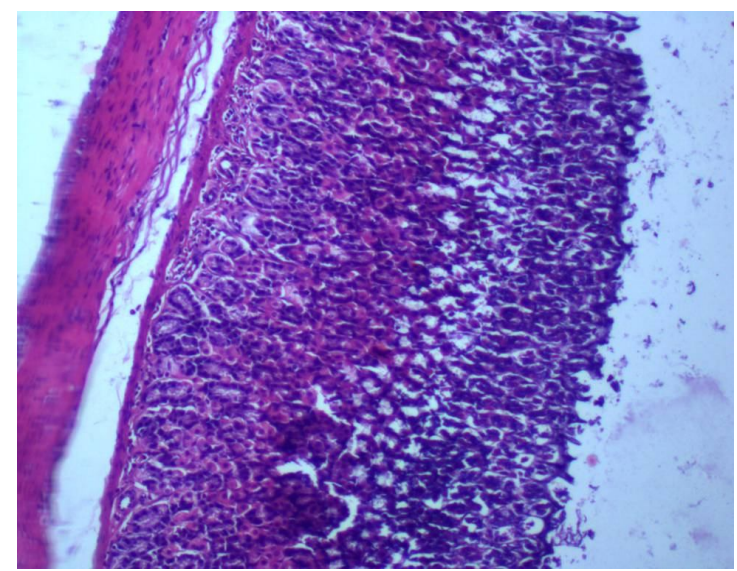

$b$

Fig. 3. Stomach of rats on the 90th day of the experiment when the intragastric administration of test compounds at a dose of $14.6 \mathrm{mg} / \mathrm{kg}$. Hematoxylin and eosin, magn. $\mathrm{x} 400$ $\mathrm{a}$ - nanosized silicon dioxide; $\mathrm{b}$ - microsized silicon dioxide 


\section{Experimental model and measurement studies}

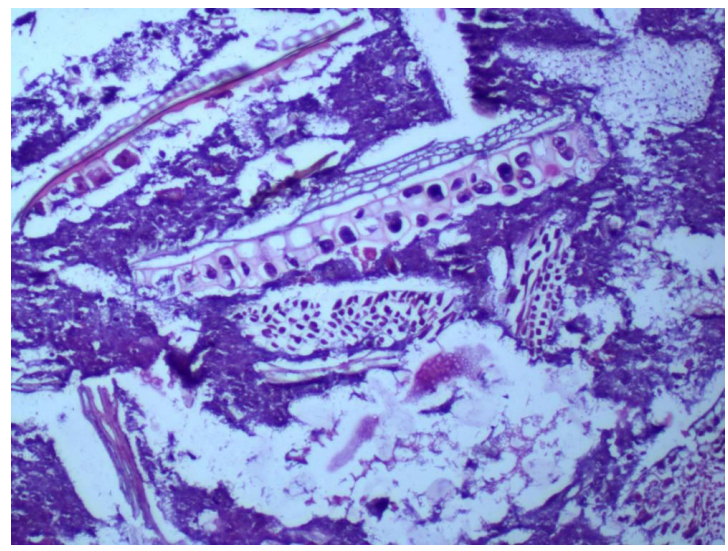

$a$

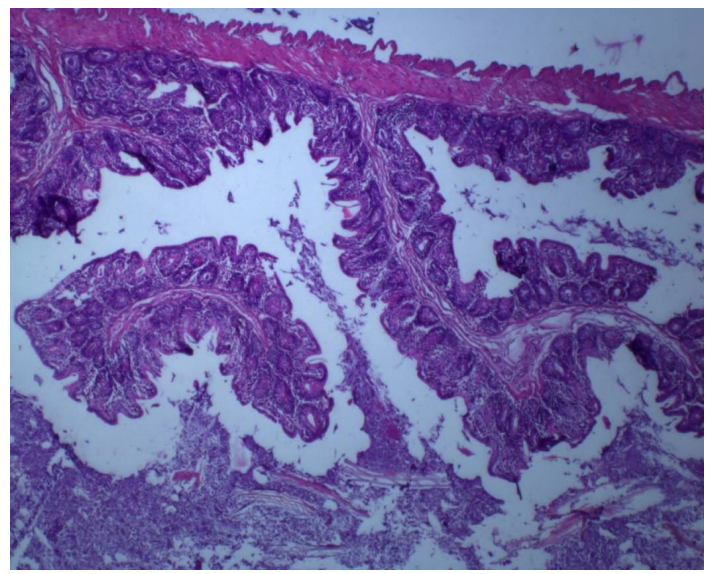

$b$

Fig. 4. Intestine colon rats on the 90th day of the experiment with the test compounds administered intragastrically at a dose of $14.6 \mathrm{mg} / \mathrm{kg}$. Hematoxylin and eosin, magn. x 200 $\mathrm{a}$ - nanosized silicon dioxide; $\mathrm{b}$ - microsized silicon dioxide

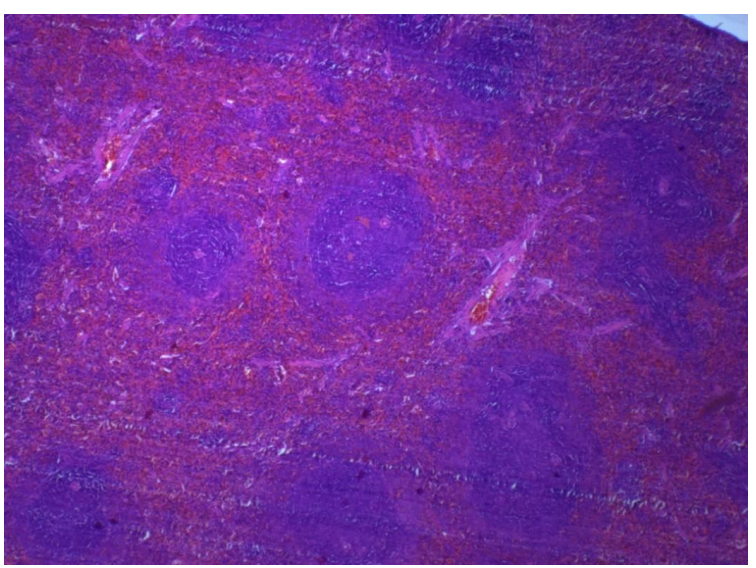

$a$

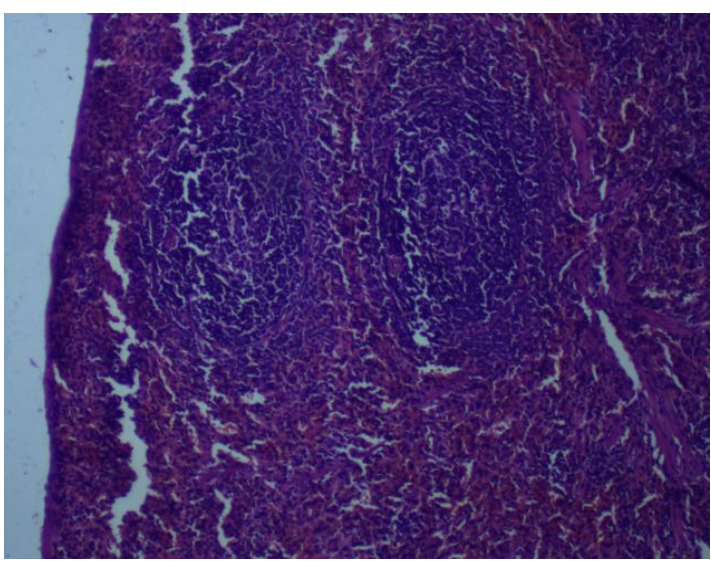

$b$

Fig. 5. Spleen of rats on the 90th day of the experiment with the test compounds administered intragastrically at a dose of $14.6 \mathrm{mg} / \mathrm{kg}$. Hematoxylin and eosin, magn. x 200 $\mathrm{a}$ - nanosized silicon dioxide; $\mathrm{b}$ - microsized silicon dioxide, magn. X 400

In the histological preparations of the colon, the wall structure is rendered unchanged. The immune irritation effect in the animals of group 1 is confirmed by a significant decrease in the eosinophilic-lymphocytic index of whole blood - by 1.5 times compared to the control group $(\mathrm{p}=0,004-0,043)$. This toxic effect is confirmed by the presence of the clusters of lymphocytes, macrophages, white blood cells and plasma cells in the spleen pulp tyazhah. In the group of animals treated with microsized silicon dioxide, deviations of this index and pathological changes in the spleen compared to controls were found (Fig. 5).

Conclusions. Consequently, the comparative evaluation of effects of subchronic toxicity of the test substances in intragastric administration for 90 days at a dose of $14.6 \mathrm{mg} / \mathrm{kg}$ showed that an aqueous suspension of nanosized silicon dioxide has a large range of toxic effects and a 
higher degree of severity compared with microsized analogue. Nanosized silicon dioxide leads to the development of cytolysis, immune irritation and inflammatory effects confirmed by a deviation compared to control biochemical (increased MDA content, lipid hydroperoxide, ALT, CRP, decreased activity of the AOC, SOD) and hematological (decreased eosinophiliclymphocytic index) data, as well as changes in the morphological structure of the cells of the liver, spleen, stomach, jejunum and middle intestine. When the microfine analogue is administered at a dose of $14.6 \mathrm{mg} / \mathrm{kg}$, we only determined inflammation effect in the gastrointestinal tract, confirmed by increased CRP and morphological changes in the mucosa of stomach, jejunum and colon.

These results are consistent with the above theoretical assumption of greater toxicity of nanosized silicon dioxide compared to its microsized analogue that must be considered in planning hygienic regulation of the content of nanoparticles in food and water.

\section{References}

1. Bljuger A.F., Majore A.Ja. Problemy perekisnogo okislenija lipidov v gepatologii [Problems of lipid peroxidation in hepatology]. Uspehi gepatologii, 1978, no. 7, pp. 22-54.

2. Glanc S. Mediko-biologicheskaja statistika [Biomedical statistics]. Ed. N.E. Buzikashvili i soavt. Moscow: Praktika, 1998. 459 p.

3. Nanoporoshki: opisanie i ob\#emy proizvodstva: Marketingovyj otchet Issledovatel'skoj kompanii «Abercade» [Nanopowders: description and production: Market Report of the Research company «Abercade». 2008]. 2008. Avaible at: URL: http: //www.abercade.ru/research/analysis/66.html.

4. Zajceva N.V., Zemljanova M.A., Zvezdin V.N., Saenko E.V. Toksikologogigienicheskaja ocenka bezopasnosti vodnoj suspenzii nanodispersnogo dioksida kremnija, sintezirovannogo metodom zhidkokristallicheskogo templatirovanija [Toxicological and hygienic evaluation of the safety of an aqueous suspension of nanopowder silica synthesized by the liquid crystal templating]. Analiz riska zdorov'ju, 2013, no. 1, pp. 65-72.

5. Guide for the care and use of laboratory animals. Eighth Edition. Committee for the Update of the Guide for the Care and Use of Laboratory Animals; Institute for Laboratory Animal Research (ILAR); Division on Earth and Life Studies (DELS); National Research Council of the national academies. Washington: The national academies press, 2011. $246 \mathrm{p}$.

6. Meynen V., Cool P., Vansant E.F. Verified syntheses of mesoporous materials. Microporous and mesoporous materials, 2009, vol. 25, pp. 170-223.

7. Donaldson K. Stone V., Tran C.K. et al. Nanotoxicology (editorial). Occupat. and Environm. Med., 2004, vol. 61, pp. 727-728.

8. Ghiazza M., Carella E., Tomatis M., Corazzari M., Cristina M. Predictive tests to evaluate oxidative potential engineered nanomaterials. Nanotechnology and nanotoxicology, Grenoble, 13-15 November 2012.

9. Bastus N.G., Casals E., Socono V.S., Puntes V. Reactivity of engineered inorganic nanoparticles and carbon nanostructures in biological media. Nanotoxicology, 2008, vol. 2, pp. 99-112. 
10. Nozawa K. Gailhanou H., Raison L., Panizza P. Smart Control of Monodisperse Stolber Silica Particles: Effect of Reactant Addition Rate on Growth Process. Langmuir, 2005, vol. 21, pp. 1516-1523.

11. Vallet-Regi M., Balas F., Arcos D. Mesoporous Materials for Drug Delivery. Angew. Chem. Int. Ed., 2007, vol. 46, pp. 7548-7558.

12. World Nanotechnology: Innovation and Technology Trends. Nanotechnology Industry Market Research Reports. 2012. Avaible at: http: //www.reportlinker.com/ci02344p2/Nanotechnology.html/mode/public 319_1.pdf. 